\title{
Numerical modeling of saturation type and lateral pressure influences on thermo-mechanical stresses caused by laser drilling in granite and limestone
}

\author{
Abdollah Dini and Morteza Ahmadi
}

${ }^{*}$ Correspondence:

moahmadi@modares.ac.ir

Rock Mechanics Group, Eng.

Faculty, Tarbiat Modares

University, Tehran, Iran

\begin{abstract}
Numerical methods for study effect of parameters on rock behaviour have increased in recent decades. Simulation is an important tool for analysis which the possibility of doing it is not feasible under experimental conditions and the possibility of analysis of thermo-mechanical stress and strain caused by the laser. In this study, the finite element method has been used to study thermal and mechanical stresses caused by drilling with laser ND: YAG in rock samples of limestone and granite. For this purpose, the software ABAQUS was used for thermal and mechanical analyses. After applying drilling rate and modeling laser drilling based on experimental tests, the effect of type of saturation and high lateral pressures on the rock laser drilling was studied. Results showed that the numerical model used is in good agreement with the experimental data. The thermo-mechanical stress developed in the rock has a direct relationship with the drilling specific energy. Also, in the limestone and granite, the maximum stress caused by laser drilling in the water-saturated rocks is higher than the oil-saturated and dry state.
\end{abstract}

Keywords: Laser drilling, Thermal and mechanical stress, ABAQUS, Finite element method, Granite, Limestone

\section{Introduction}

Research studies in the field of laser drilling in petroleum reservoirs especially in perforation of the casing in shale gas and oil wells have been underway since 1960. The results obtained by a huge number of studies show that the laser perforating method is possible for deep wells $[1,2]$, but the application of the technology is still under question. Some advantages of laser drilling rock removal are as following:

1. The permeability of reservoir rock increases by creating fractures,

2. Rock is removed by drilling, so it is the most energy efficient,

3. The process is easy on beam fibre optical cable delivery due to low laser power required for each spalling beam and,

4. Small rock fragments are readily flushed out by standard well flushing method [3, 4]. 
However, in order to take advantage of laser drilling, recent research studies focus on the applications of advanced high power lasers for drilling and completion of gas and oil wells [5].

Laser effect appears in two steps in rocks, firstly, it creates holes in the rock and secondary include melting, evaporation, laser beam gases and micro fractures. The high temperature associated with laser drilling process continuously changes the physical and chemical properties of rocks. A sudden increase in the rock temperature results in expansion of its grains. As the closely-packed grains in the rock matrix expand with a rapid rise in temperature, they develop thermal stress, fractures and cracks within the grains as well as breaking the cementation of adjacent grains. As a result, an affected grain will begin to break free from one another [6]. Mechanism of rock drilling by the laser is shown in Fig. 1.

Laser rock drilling is a very complex phenomenon that depends on many factors. In case of the oil and gas reservoirs, thermo-mechanical stress of rocks under in situ pressure and temperature conditions is the most important key parameter for estimations of temperature increase of the rocks around the holes associated to generation of heat by laser spallation. The physical properties of rocks, including thermal conductivity, are dependent on stress and temperature, so in situ pressure and temperature conditions should be simulated in laboratory measurements and numerical modeling of drill core samples. Numerical modelling, however, can establish a virtual experiment and simulate the effect of factors that are difficult to study by a real experiment [7]. Several numerical studies have been conducted in laser spallation.

$\mathrm{Xu}$ et al. [7] modelled laser drilling as in the two-dimensional environment and examined the chemical and microscopic effects of rock. Agha et al. [8] developed a finite element model to predict the rate and depth of penetration during laser machining without consideration of melting. This model ignored inhomogeneities within the rock. A more inclusive model developed by Walsh et al. [9] focused on the behavior of granitic rock on a grain scale level during hydrothermal spallation. Damian et al. [10] modelled thermomechanical effects on laser-rock interaction. They posited how all physical phenomena can be coupled in a comprehensive numerical model. Rehema et al. [11] presented a numerical model of laser spallation of heterogeneous granitic rock using the finite

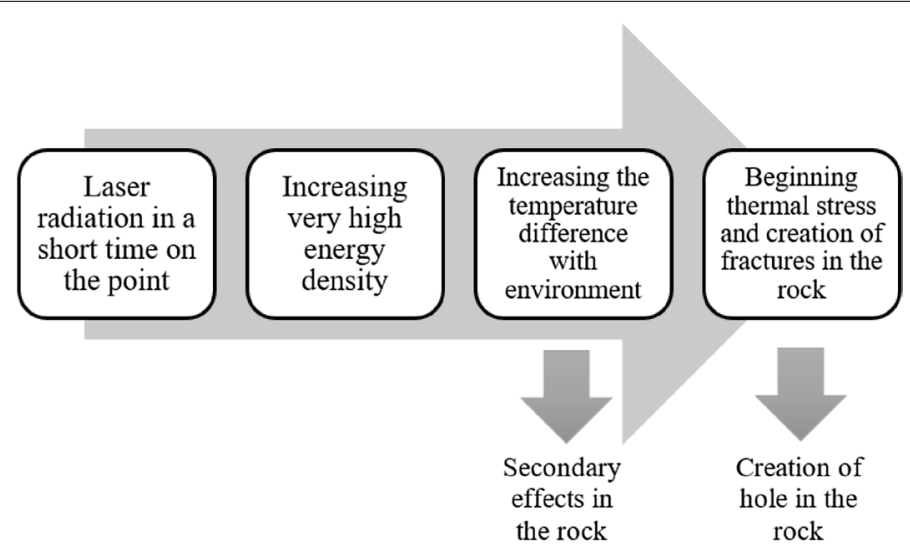

Fig. 1 Mechanism of creation a hole in the rock by laser 
element method (FEM). The developed model accounts for the presence of micro-cracks within the rock and the effect of propagation of these cracks on spallation is investigated regarding temperature and stress profiles generated.

There is very little research reported on the effect of confining pressure and type of saturation in rock perforating using lasers. Ahmadi et al. [2,12] examined the effect of different types of saturation and lateral pressure on specific energy levels and penetration rate, But, due to experimental limitations, the distribution of heat and mechanicalthermal stresses, which were caused by the laser, have not been studied.

In this present paper, the results of numerical modeling are compared with experimental data conducted by Ahmadi et al. The main purpose of this paper is to analyze the effect of lateral pressure and type of saturation on thermal and mechanical stresses that were induced by ND: YAG laser drilling on rock samples.

\section{Numerical modeling}

ABAQUS has been a popular program for modelling laser drilling due to its features and capabilities [13-15]. Some of the features include having a user-friendly graphical environment, the definition of thermal and mechanical parameters of various materials easily, having a full library of mesh partitions required by the type of analysis, ability to analyse stress, strain and heat distribution for laser drilling and showing the output of modelling graphically with understandable diagrams and figures. In order to understand the process of calculations, theoretical analysis of mechanical and thermal stresses using the finite element method is given below.

\section{Thermal and mechanical stress analysis}

ABAQUS software is based on the finite element method, where the equation of thermal stresses due to laser pulse heating can be achieved through stress-strain relations. Assuming that external mechanical stresses are induced on the specimen surface, thermal stress relationships in cylindrical coordinates are as follows $[16,17]$ :

$$
\begin{gathered}
\sigma_{r}=\frac{\varphi}{r} \\
\sigma_{\theta}=\frac{d \varphi}{d r}
\end{gathered}
$$

where, $\varphi$ is the stress function. In the case of plane strain, the strain in the Z-axis is equal to zero, and stress is calculated according to Eq. 3, thus [17]:

$$
\sigma_{Z}=v\left(\sigma_{r}+\sigma_{\theta}\right) \times \alpha_{T} E T
$$

where, E, $v$ and $\alpha_{T}$ are elastic modulus, Poisson's ratio and coefficient of thermal expansion of rock, respectively. Compatibility equation for axisymmetric mode is as below:

$$
r\left(\frac{d \varepsilon_{\theta}}{d r}\right)+\varepsilon_{\theta} \times \varepsilon_{r}=0
$$

To simplify the calculations, the starred (*) relations are used to indicate a mode of equivalent stress. This means that, by applying the coefficients to each parameter, the 
parameter becomes dimensionless. Finally, thermal stress is calculated using the following equations:

$$
\begin{aligned}
& \sigma_{r}^{*}=\frac{1}{r^{* 2}} \int_{g^{*}}^{r^{*}} T^{*} r^{*} d r^{*} \\
& \sigma_{\theta}^{*}=\frac{1}{r^{* 2}} \int_{g^{*}}^{r^{*}} T^{*} r^{*} d r^{*} \times T^{*} r^{* 2} \\
& \sigma_{Z}^{*}=T^{*}
\end{aligned}
$$

And the equivalent stress is as follows:

$$
\sigma_{e}^{*}=\sqrt{\frac{1}{2}}\left[\left(\sigma_{r}^{*} \times \sigma_{\theta}^{*}\right)^{2}+\left(\sigma_{r}^{*} \times \sigma_{Z}^{*}\right)^{2}+\left(\sigma_{Z}^{*} \times \sigma_{\theta}^{*}\right)^{2}\right]
$$

In ABAQUS software, by defining the thermal expansion coefficient ( $\alpha$ ) for any homogeneous solid body, the heat and time-dependent displacement analysis can be implemented [18].

\section{Model geometry and type of elements meshing}

Because the sample is loaded with axial symmetry, the model geometry was created as axisymmetric or axial symmetry. The models are generated as cylinders with the radius of $54 \mathrm{~mm}$ and the height of $50 \mathrm{~mm}$. After creating the model geometry, elements type are selected. According to mesh surveys, four-node rectangular elements, i.e. CAX4T, were used and the model was divided into 2142 elements. In Fig. 2, a view of the model geometry and the presumed location of the laser beam as well as coordinates of its starting point are displayed.

In the stress investigation, displacements are saved by ABAQUS at the nodal points as a solution variable, and loads are determined as prescribed displacements and forces. The temperature-time history resulting from the thermal analysis is used as input to the thermal stress analysis. The workpiece is supposed to be an elastic body, which is modelled as von Mises elastic-plastic material with isotropic hardening and with a yield stress that changes with temperature.

Specifications of the laser are presented in Table 1. To model the laser power, the drilling rate obtained from Ahmadi et al. [2] tests has been considered.

\section{Material properties}

The material properties can have a great impact on the accuracy of numerical modelling. Mechanical properties of limestone and granite samples are presented in Table 2.

Also, thermal properties of limestone and granite samples in dry, water-saturated and oil-saturated conditions are shown in Tables 3 and 4. The amount of coefficient of thermal expansion, specific heat capacity and heat transfer coefficient are obtained through thermal properties testing and verified by statistical analysis. To evaluate the thermal 


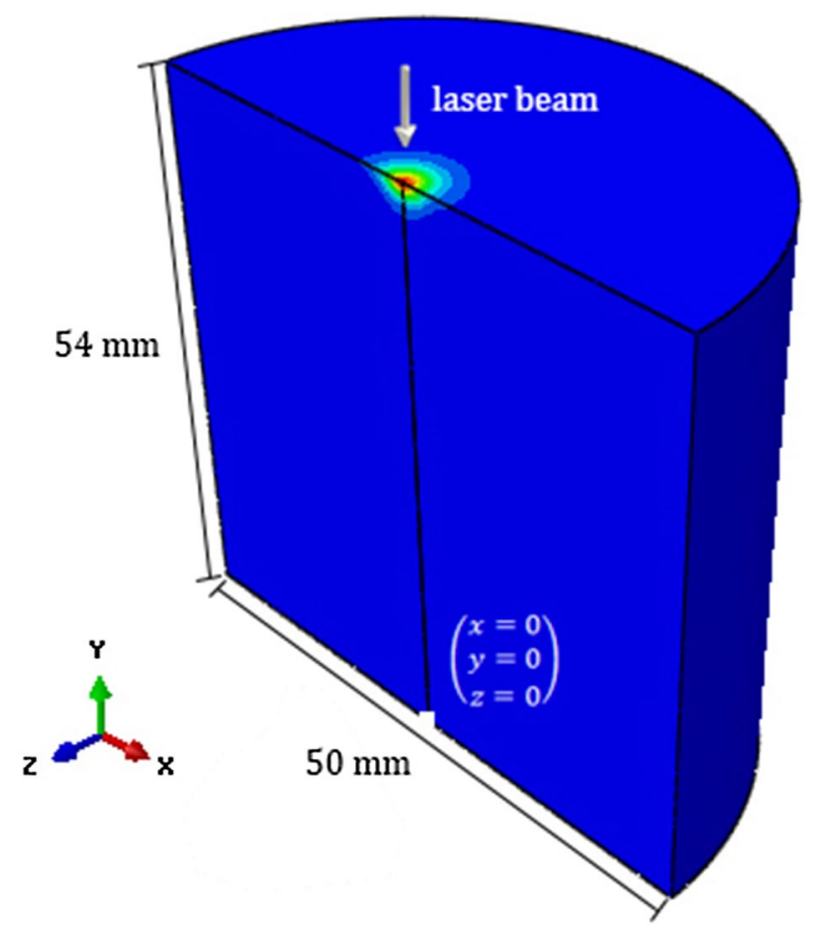

Fig. 2 A view of the geometry of model and location for applying laser beam

Table 1 Laser specifications n numerical analysis [2]

\begin{tabular}{lllll}
\hline Frequency $(\mathrm{Hz})$ & Wave length $(\mathbf{n m})$ & Pulse width $(\mathbf{m s})$ & Blower gas & Gas pressure (bar) \\
\hline 30 & 1064 & 2 & Nitrogen & 3 \\
\hline
\end{tabular}

Table 2 Geomechanical properties of samples [2]

\begin{tabular}{lll}
\hline Parameter & Limestone & Granite \\
\hline Modulus of elasticity $(\mathrm{Pa})$ & $16 \mathrm{e} 9$ & $55 \mathrm{e} 9$ \\
Poisson's ratio $(\mathrm{v})$ & 0.25 & 0.2 \\
Density $\left(\mathrm{kg} / \mathrm{m}^{3}\right)$ & 2225 & 2660 \\
\hline
\end{tabular}

Table 3 Thermal parameters of limestone

\begin{tabular}{llll}
\hline Thermal parameters & Dry & Water-saturated & Oil-saturated \\
\hline Thermal expansion coefficient $(\mathrm{m} / \mathrm{mK})$ & $8 \mathrm{e}-6$ & $8.4 \mathrm{e}-5$ & $3.4 \mathrm{e}-5$ \\
Specific heat capacity $(\mathrm{J} / \mathrm{kgK})$ & 908 & 877 & 872 \\
Heat transfer coefficient $(\mathrm{W} / \mathrm{mK})$ & 1.21 & 1.27 & 1.23 \\
Density $\left(\mathrm{kg} / \mathrm{m}^{3}\right)$ & 2225 & 2245 & 2242 \\
\hline
\end{tabular}

expansion coefficient, thermal strain was measured with strain gauges glued to the samples in an environmental chamber. The measured thermal strain is converted to a thermal expansion coefficient by the relation of temperature to thermal strain. The specific 
Table 4 Thermal parameters of granite

\begin{tabular}{llll}
\hline Thermal parameters & Dry & Water-saturated & Oil-saturated \\
\hline Thermal expansion coefficient $(\mathrm{m} / \mathrm{mK})$ & $7.9 \mathrm{e}-6$ & $5 \mathrm{e}-5$ & $2.2 \mathrm{e}-5$ \\
Specific heat capacity $(\mathrm{J} / \mathrm{kgK})$ & 800 & 783 & 783 \\
Heat transfer coefficient $(\mathrm{W} / \mathrm{mK})$ & 3.32 & 3.34 & 3.37 \\
Density $\left(\mathrm{kg} / \mathrm{m}^{3}\right)$ & 2660 & 2664 & 2663 \\
\hline
\end{tabular}

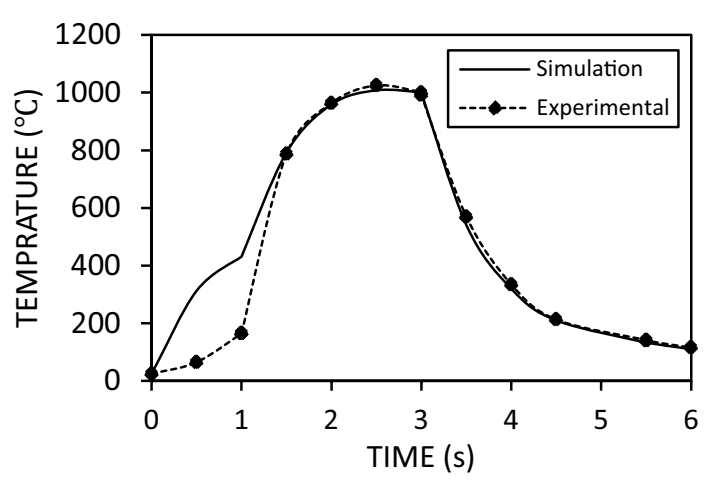

Fig. 3 Comparison of the laser drilling heat distribution in numerical models and experimental for limestone

heat was measured using the DSC system at room temperature. The results were calibrated with Synthetic Sapphire. Heat transfer coefficient was measured with the transient hot-wire method at room temperature. The result was verified with soda glasses, which are well known for their heat transfer coefficients.

\section{Results and discussion}

In order to validate the heat distribution results obtained from ABAQUS software, the temperature of the models generated by this software was increased to $1200{ }^{\circ} \mathrm{C}$ and the outputs were compared with the experimental data, as shown in Fig. 3. As it can be seen, there is a good agreement between the numerical and experimental results of Salehi et al. [6].

\section{The effect of lateral pressure}

In order to investigate the effect of different lateral pressures and compare them with the previous experimental studies, pressures of 8, 16, 24, 32 and $37 \mathrm{MPa}$ were applied to limestone models. Ahmadi et al. [2] results were used to simulate the laser-drilling penetration rates for the model generated by ABAQUS software.

Research indicated that in rock perforating with laser, specific energy (SE) is the most important factors. Specific energy is defined as the amount of energy required to remove a unit weight of rock $[1,2]$ and is represented as

$$
S E=\frac{E_{i}}{V_{r}}
$$



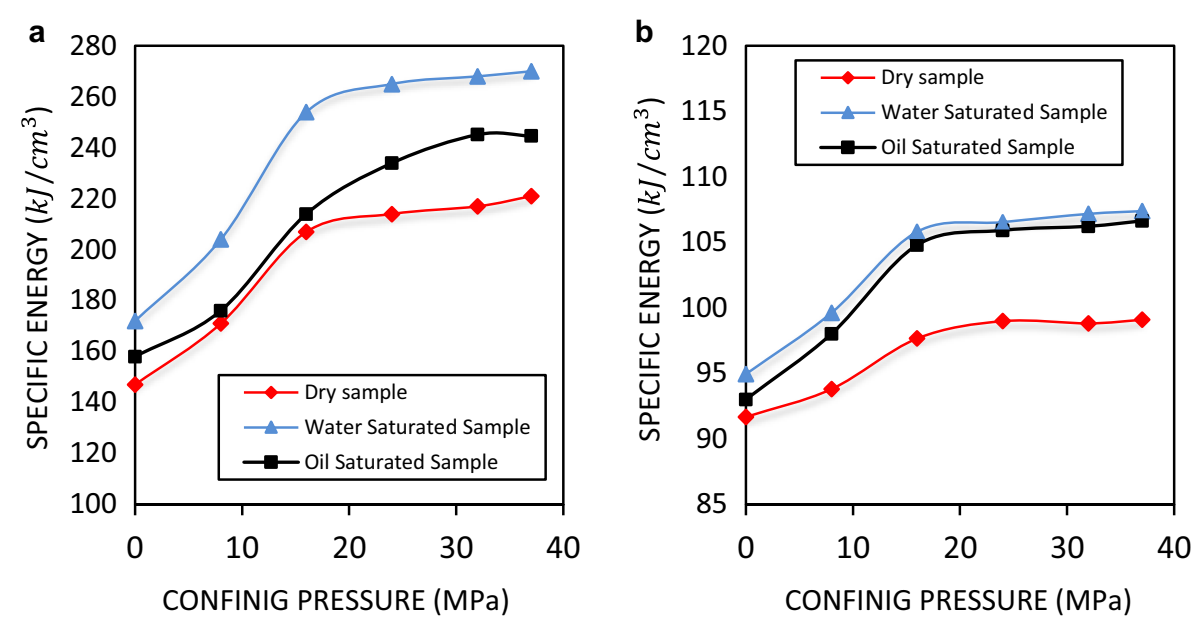

Fig. 4 Specific energy-graph at different lateral pressures for samples of granite (a) and limestone (b) [2]
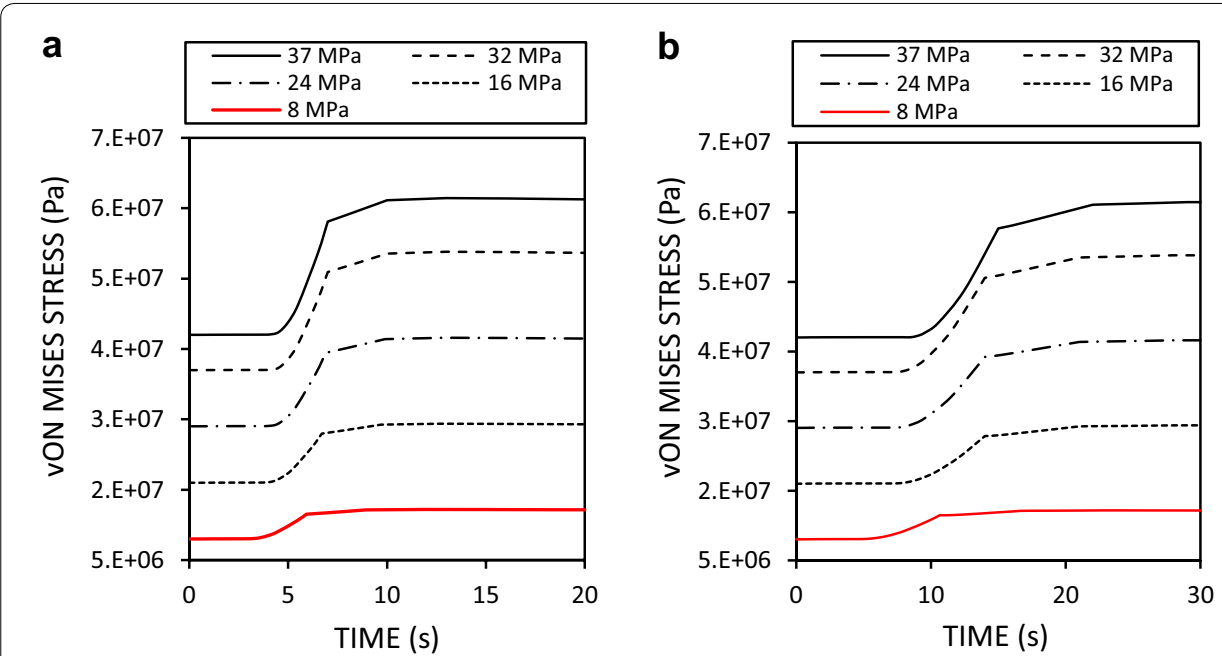

Fig. 5 Stress-time curve under different lateral pressures for dry samples of granite $(\mathbf{a})$ and limestone $(\mathbf{b})$ in Point $\mathrm{A}(\mathrm{x}=1.5 \mathrm{~mm}, \mathrm{y}=50 \mathrm{~mm})$

where $S E$ is the specific energy and $E_{i}$ and $V_{r}$ are the input energy (per joules) and the removed volume of the rock (per cubic centimeters), respectively.

Figure 4 shows the specific energy graphs at different lateral pressures for granite and limestone samples [2]. According to this figure, a clear trend exists for all three conditions of dry, saturated with water, and saturated with crude oil, in which with the increase in lateral pressure, the specific energy (SE) consumption increases at the beginning of the laser application, and continues at a roughly constant rate to the end. Specific energy increases with higher rates at the pressures between 0 and $16 \mathrm{MPa}$.

A question derived from the experimental results is how much thermo-mechanical stress is induced by laser drilling? Figure 5 shows the stresses generated around a hole drilled by laser drilling operation under the different confining pressures for dry 
granite and limestone. As expected, with the increase in the amount of lateral pressure, the thermo-mechanical stresses around the hole was also increased. The sharp points in the graphs indicate a sudden change in the temperature and the instant rock removal caused by the laser.

One reason for the increase in the stress and strain is associated with thermal stress, which is the more significant parameter in spallation of the samples in the laser drilling method. This also means that, over a short time period, the temperature difference between adjacent elements is huge. For this reason, the induced stress (thermal stress) broke the samples and made the elimination of material easier. With an increase in the lateral pressure, the distance between sample particles (grains of rock) decreases and leads to an enhancement of the thermal conductivity. An increasing thermal conductivity causes to decrease the thermal stress, which is another reason for the increase in SE and the decrease in rate of penetration (ROP) that is observed with increasing enhancing confining pressure. Figure 6, for instance, shows the stress distribution formed by laser drilling for dry limestone model at a lateral pressure of $32 \mathrm{MPa}$ in two times $(10 \mathrm{~s}$ and $25 \mathrm{~s}$ ).

Figure 7 shows a graph of temperature versus time under confining pressures of 8,16 , 24, 32 and $37 \mathrm{MPa}$ for rocks. In these graphs, with the increase in lateral pressure, temperature increases, but no significant changes in temperature can be observed at confining pressures over $32 \mathrm{MPa}$. Thus, it can be concluded that the heat distribution in rock samples is less sensitive to high lateral pressure changes. Although, in Fig. 7, temperature changes versus time seem to be relatively stable under different lateral pressures, the maximum temperature of the laser at each level of pressure varies.

Although the overall trend of temperature changes on granite and limestone is the same, while the maximum temperature and the time of heating and cooling are different. Limestone temperature increased sharply and peaked to nearly $1200{ }^{\circ} \mathrm{C}$ until $4 \mathrm{~s}$, then fell very quickly to the initial temperature during $15 \mathrm{~s}$, whereas the highest temperature of granite reached to approximately $1400{ }^{\circ} \mathrm{C}$ and the process of heating and cooling continued around $25 \mathrm{~s}$.

In Fig. 8a, b, respectively, thermo-mechanical stresses and strain diagrams are shown for various lateral pressures. As it can be seen, with the increase of pressure,

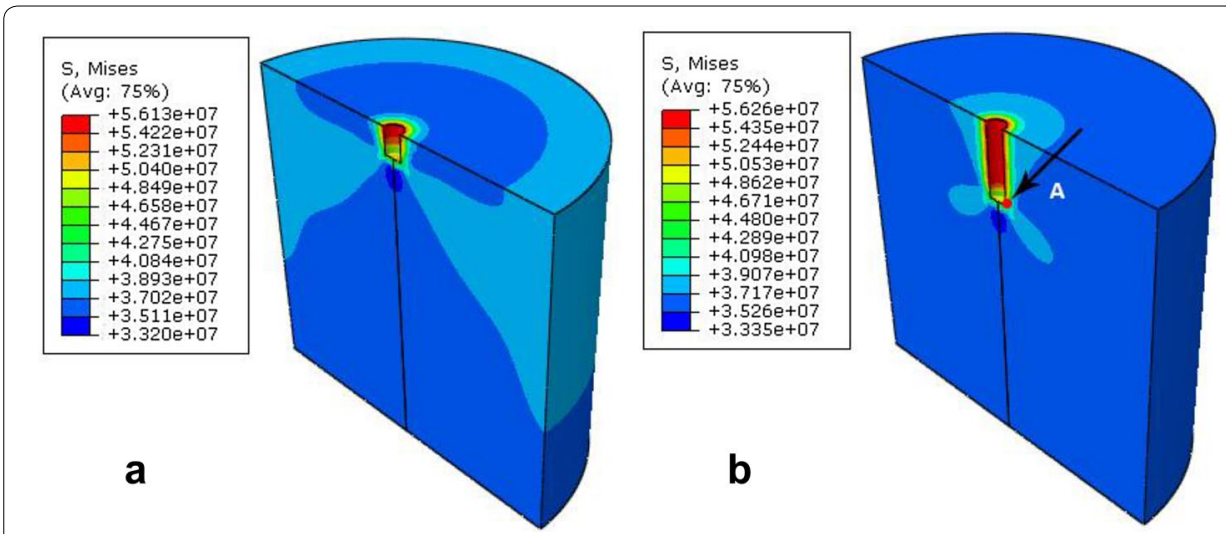

Fig. 6 Von Mises stress distribution caused by laser drilling at a lateral pressure of 32 MPa for dry limestone sample in a time of $10 \mathrm{~s}(\mathbf{a})$ and $25 \mathrm{~s}(\mathbf{b})$ 

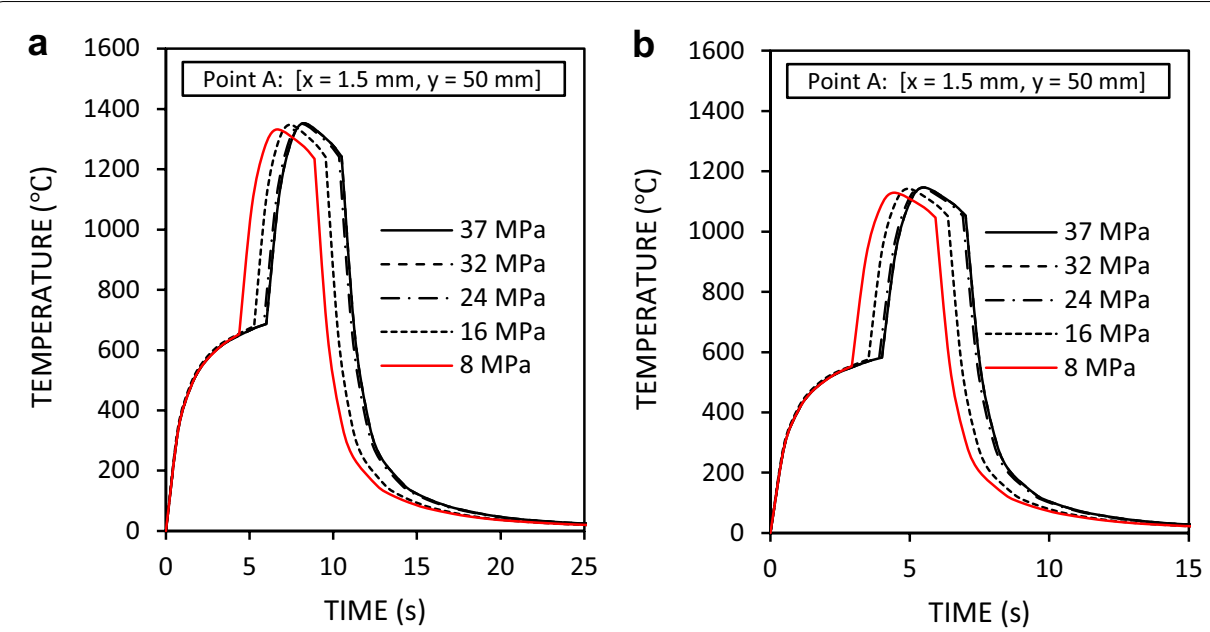

Fig. 7 Temperature versus time graph under different lateral pressures for samples of granite (a) and limestone $(\mathbf{b})$ in point A
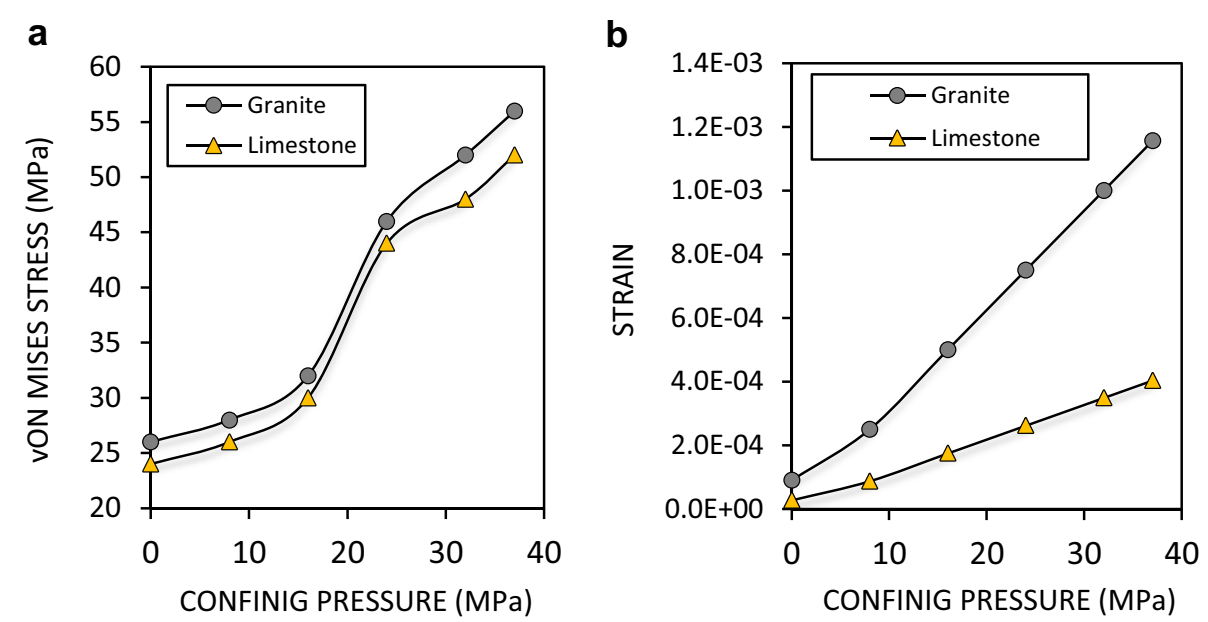

Fig. 8 a Laser-induced stress and $\mathbf{b}$ strain diagram under different lateral pressures for samples of granite and limestone in point $\mathrm{A}$

the value of stress and strain in both rock samples increase. This increase in the von Mises stress and strain values are higher in granite samples rather than limestone samples. Based on this figure, the thermo-mechanical stress will increase suddenly at confining pressure of $16 \mathrm{MPa}$ but will have a slight trend at higher confining pressure.

\section{Effect of saturation type}

Saturation effect in samples of limestone and granite on the specific energy of drilling was conducted experimentally by Ahmadi et al. [12]. Experimental results have shown that the types of saturation influence the specific energy, such that water saturated samples required as higher specific energy than heavy oil saturated samples and 

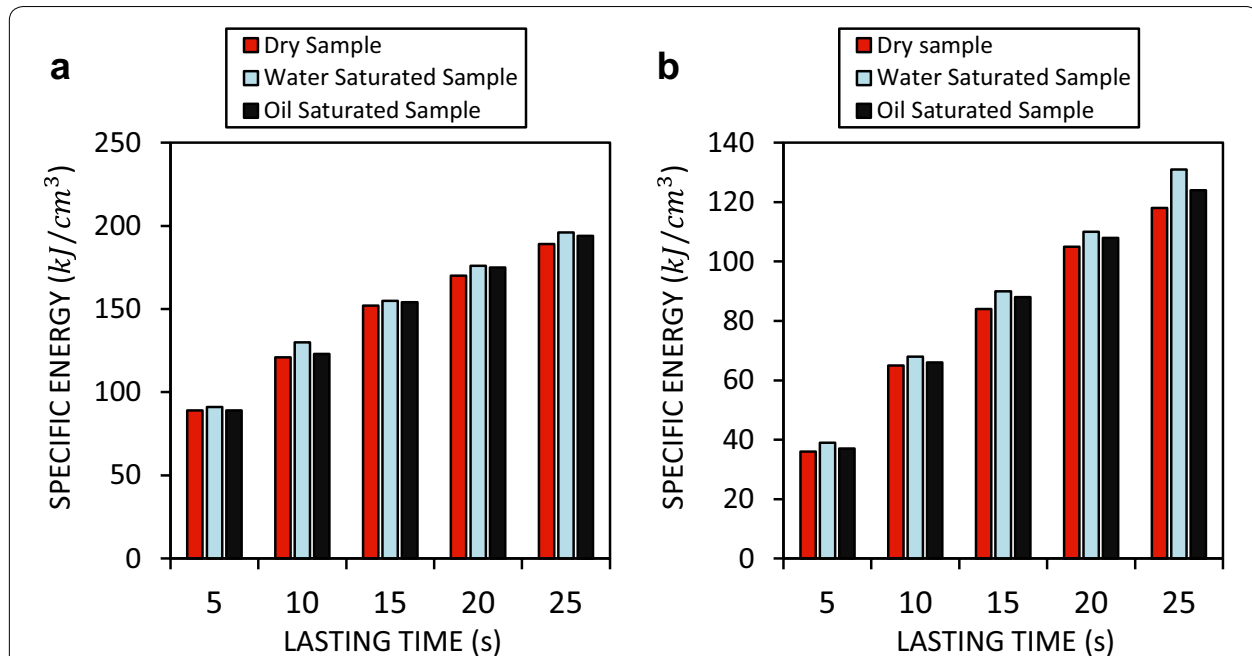

Fig. 9 Drilling specific energy per unit of time, for samples of granite (a) and limestone (b) in dry, water saturated and oil saturated conditions [12]

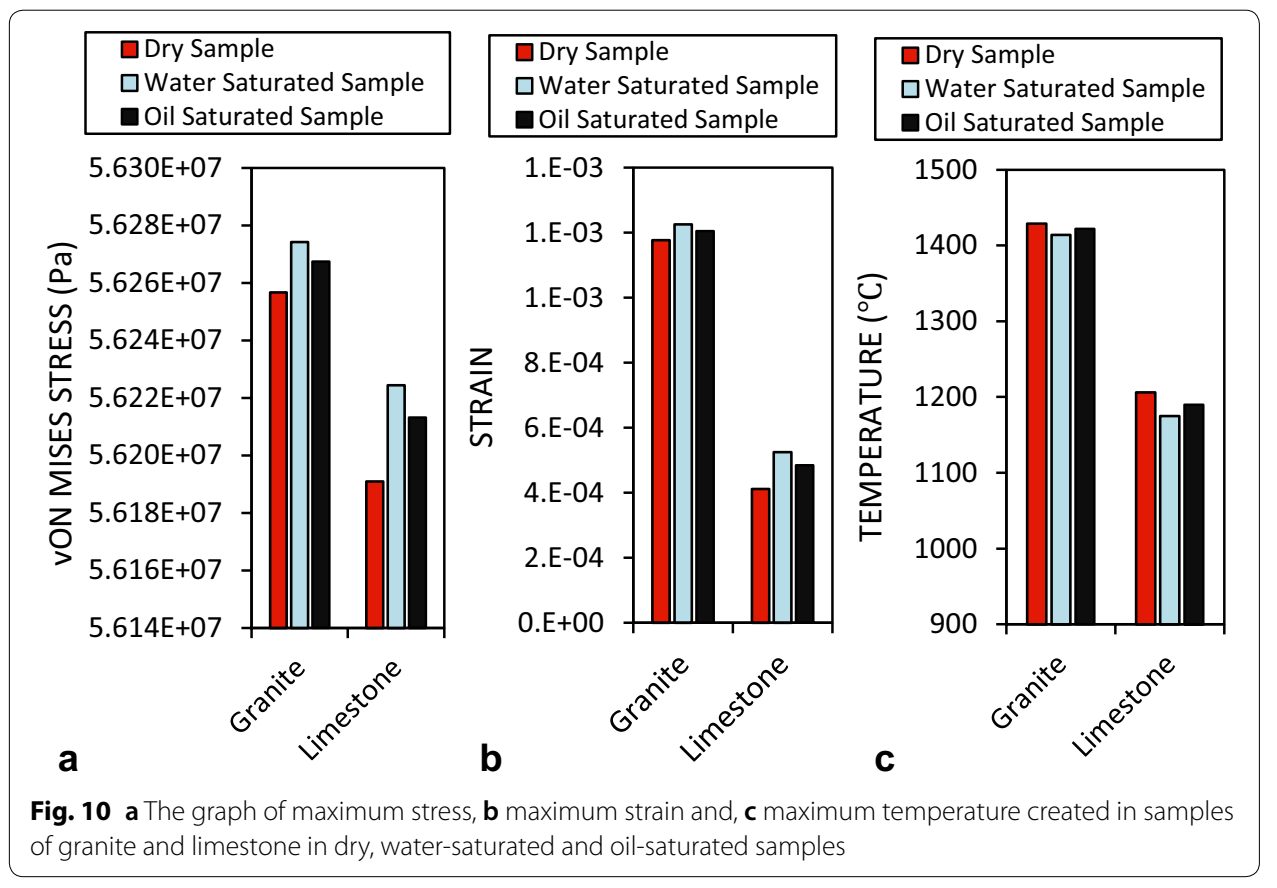

the heavy oil saturated samples need more SE than the dry samples. In Fig. 9, the effect of saturation per unit of time is shown for limestone and granite samples.

With regard to the above experimental results, the question arises as what is the reason for the enhancement of the specific energy in saturated samples? Figure 10 is provided to respond to this query. In Fig. 10, the maximum stress, strain, and temperature are shown for the dry, water saturated, oil-saturated conditions of limestone and granite samples. Thermal parameters for the dry, water-saturated, oil-saturated conditions were defined in the numerical model in order to evaluate the influence of saturation type on the mechanical and thermal stresses caused by the laser. As it can be seen, the values 
of maximum stress and strain that are caused by laser drilling are highest water saturated condition in and lowest in dry condition. By comparing the data from experimental works and numerical modelling, it can be concluded that the amount of stress and strain created by laser drilling are correlated with the amount of specific energy, i.e. the amount of thermo-mechanical stress in the rock increase with an increase in the specific energy. It should be mentioned that there is a direct relation between the increased thermal stress and the existence of the porosity and fractures in the samples because, in the rock saturation, the absorbed liquid fills the empty spaces of the rock created by as porosity and fractures. When the porosity and fractures of a sample increase more liquid volume are present in the sample and more laser energy is needed to vaporise this liquid and consequently, more thermal stress induced.

As Fig. 10 shows, there is an obvious discrepancy between the temperature of water and heavy oil saturated samples compared to the dry ones. The temperature for the water saturated samples is less than the heavy oil saturated ones because the vaporisation point of water is higher than the oil. Moreover, the thermal capacity of water is more than the heavy oil and so vaporisation of water needs less temperature. Another reason for this difference is the higher absorption of the laser energy of heavy oil compared to that of water.

As well as, Limestone is more sensitive to saturation than granite and it is because of higher porosity of limestone. Not surprisingly, the amount of maximum stress, strain and temperature in granite are much more than limestone samples because of the different thermal and mechanical properties of these rocks.

\section{Conclusions}

Numerical modelling of laser perforation on limestone and granite samples were performed for the study of thermal and mechanical stresses. With an increase in confining pressure, the thermo-mechanical stress increases rapidly within the range $16 \mathrm{MPa}$, whereas temperature is relatively stable under high lateral pressures over the same range. Stronger samples have higher thermo-mechanical stress and strain. In limestone and granite samples, higher stresses were generated in the saturated samples compared to dry samples as a result of laser drilling, while maximum temperature created in watersaturated samples are less than dry and oil-saturated samples. It can thus be concluded that the thermo-mechanical stress and strain developed in the rock has a direct relationship with the drilling specific energy, in which the quantity of essential specific energy, thermo-mechanical stress and strain increases, with an increase in the amount of compressive strength. Also, the finite element method can be considered as an efficient tool for analysing temperature and thermo-mechanical stresses induced by laser drilling due to fast response and high performance.

Authors' contributions

AD has collected required field data and then did the numerical modeling. MA, the supervisor, analysed the software outputs. Both authors read and approved the final manuscript. 


\section{Publisher's Note}

Springer Nature remains neutral with regard to jurisdictional claims in published maps and institutional affiliations.

Received: 26 April 2018 Accepted: 20 August 2018

Published online: 06 September 2018

\section{References}

1. Xu Z, Reed CB, Konercki G, Gahan BC, Parker R, Batarseh S (2003) Specific energy for pulsed laser rock drilling. J Laser Appl 15(1):25-30. https://doi.org/10.2351/1.1536641

2. Ahmadi M, Erfan MR, Torkamany MJ, Sabbaghzadeh J (2012) The effect of confining pressure on specific energy in Nd: YAG laser perforating of rock. Opt Laser Technol 44(1):57-62. https://doi.org/10.1016/j.optlastec.2011.05.017

3. Brian C, Gahan BC, Richard A, Parker R, Graves R, Batarseh B (2001) Laser drilling: drilling with the power of light phase 1: feasibility study. Institute Of Gas Technology, Des Plaines. https://doi.org/10.2172/924031

4. Brian C, Gahan BC, Batarseh S (2005) Laser drilling: drilling with the power of light. Des Plaines, Gas Technology Institute. https://doi.org/10.2172/895927

5. Xu Z, Reed CB, Parker R, Graves R (2004) Laser drilling of rocks for oil well drilling. In: Proceedings of 23rd international congress on applications of laser and electro-optics. San Francisco, California

6. Salehi IA, Brian C, Gahan BC, Batarseh S (2007) Laser drilling: drilling with the power of light. Des Plaines, Gas Technology Institute. https://doi.org/10.2172/926665

7. Xu Z, Yamashita Y, Reed CB (2005) Modeling of laser spallation drilling of rocks for gas and oil well drilling. In: SPE annual technical conference and exhibition. 9-12 October, Dallas, Texas https://doi.org/10.2118/95746-MS

8. Agha KR, Belhaj HA, Mustafiz S, Bjorndalen N, Islam MR (2004) Numerical investigation of the prospects of high energy laser in drilling oil and gas wells. Pet Sci Technol 22(9-10):1173-1186. https://doi.org/10.1081/LFT-20003 4061

9. Walsh S.D, Lomov I, Kanarska Y, Roberts JJ (2012) Simulation tools for modeling thermal spallation drilling on multiple scales. In: Technical report, Lawrence Livermore Nation al Laboratory (LLNL), Livermore, CA https://www.osti. gov/servlets/purl/1113520

10. San-Román-Alerigi DP, Batarseh SI, Yanhui H (2016) Numerical modeling of thermal and mechanical effects in laserrock interaction - an overview. In: 50th US Rock mechanics/geomechanics symposium. 26-29 June, Houston, Texas, ARMA-2016-142 https://www.onepetro.org/conference-paper/ARMA-2016-142

11. Ndeda RA, Sebusang SE, Marumo R, Ogur EO (2017) Numerical model of laser spallation drilling of inhomogeneous rock. IFAC PapersOnLine 50-2:43-46. https://doi.org/10.1016/j.ifacol.2017.12.008

12. Ahmadi M, Erfan MR, Torkamany MJ, Safian GhA (2011) The effect of interaction time and saturation of rock on specific energy in ND:YAG laser perforating. Opt Laser Technol 43(1):226-231. https://doi.org/10.1016/j.optla stec.2010.06.018

13. Yilbas B, Arif A, Abdul Aleem B (2010) Laser cutting off sharp edge: thermal stress analysis. Opt Lasers Eng 48(1):1019. https://doi.org/10.1016/j.optlaseng.2009.03.006

14. Yilbas B, Akhtar S (2011) Laser cutting of Kevlar laminates and thermal stress formed at cutting sections. Opt Lasers Eng 50:204-209. https://doi.org/10.1016/j.optlaseng.2011.09.004

15. Yilbas B, Ahktar S, Chatwin C (2011) Laser hole cutting into bronze: thermal stress analysis. Opt Laser Technol 43(7):1119-1127. https://doi.org/10.1016/j.optlastec.2011.02.009

16. Timenshenko SP (1984) Theory of elasticity, 3rd edn. McGraw-Hill, Singapore, pp 476-484

17. Yilbas B, Naqvi I (2003) Laser heating including the phase change process and thermal stress generation in relation to drilling. Proc Inst Mech Eng Part B J Eng Manuf. 217(7):977-991. https://doi.org/10.1243/09544050360686842

18. ABAQUS Inc (2012) ABAQUS Theory manual. Version 6.2. ABAQUS Inc, Alto

\section{Submit your manuscript to a SpringerOpen ${ }^{\circ}$ journal and benefit from:}

- Convenient online submission

- Rigorous peer review

- Open access: articles freely available online

- High visibility within the field

- Retaining the copyright to your article

Submit your next manuscript at $>$ springeropen.com 